\title{
The purpose of purpose bij besluitvorming
}

\author{
Reactie op de bijdrage van L. Timmerman aan de bundel Bestuursbeshuiten
}

\author{
Mr.J. Nijland*
}

De auteur analyseert het begrip purpose naar aanleiding van een pleidooi tot de incorporatie van dit begrip in het $\mathrm{Ne}$ derlandse ondernemingsrecht van Vino Timmerman. Auteur onderschrijft de voorgestane incorporatie, maar meent in tegenstelling tot Timmerman dat opname daarvan in de statuten de voorkeur beeft.

\section{Inleiding}

Waartoe is de vennootschap op aarde? Deze vraag staat weer in de belangstelling. Zie bijvoorbeeld het statement van de Amerikaanse Business Roundtable in augustus 2019 over het begrip purpose. ${ }^{1}$ Ook in Nederland wordt over het wezen van de vennootschap nagedacht, getuige de oproep van 25 Nederlandse hoogleraren in 2020 om responsible corporate citizenship te introduceren in de wettelijke taakopdracht van bestuurders en commissarissen ${ }^{2}$ en de oratie van Timmerman in 2020 in dit tijdschrift over de geschiedenis en toekomst van de vennootschap en de daarmee verbonden onderneming. ${ }^{3}$

Deze bijdrage schrijf ik naar aanleiding van het artikel van Timmerman getiteld 'Purpose in de managementleer en het vennootschapsrecht' in de bundel Bestuursbesluiten, waarin hij een warm pleidooi houdt voor de incorporatie van het begrip purpose in het Nederlandse ondernemingsrecht. ${ }^{4}$

De ideeën van Timmerman over purpose passen bij recente ontwikkelingen waarbij terecht steeds meer nadruk lijkt te worden gelegd op verduurzaming van de wereld op het gebied

Mr. J. Nijland is werkzaam bij de afdeling Ondernemingsrecht van de Universiteit Leiden, als Meijers fellow verbonden aan het onderzoeksprogramma Coherent Privaatrecht en redacteur van dit tijdschrift.

1 Zie www.businessroundtable.org/business-roundtable-redefines-thepurpose-of-a-corporation-to-promote-an-economy-that-serves-allamericans.

2 J.W. Winter e.a., Naar een zorgplicht voor bestuurders en commissarissen tot verantwoordelijke deelname aan het maatschappelijk verkeer, Ondernemingsrecht 2020/86.

3 L. Timmerman, Uitdagingen voor het ondernemingsrecht: op weg naar een echt ondernemingsrecht, MvO 2020, p. 133-141.

4 Zie L. Timmerman, Purpose in de managementleer en het vennootschapsrecht, in: J.M. de Jongh e.a. (red.), Bestuursbesluiten (IVOR nr. 123), Deventer: Wolters Kluwer 2021, p. 41-47. van klimaat en het verminderen van sociale ongelijkheid. ${ }^{5} \mathrm{Zijn}$ op de managementleer voortbouwende benadering van de formulering van een raison d'être, een purpose voor de door een vennootschap gedreven onderneming, roept wel enkele vragen op. Wat is een purpose? Hoe verhoudt de purpose zich tot reeds bestaande concepten zoals de statutaire doelstelling, het mission statement of het door vennootschappen gevoerde beleid ten aanzien van maatschappelijk verantwoord ondernemen? Moet de purpose wel of niet worden opgenomen in de statuten? In hoeverre is sprake van greenwashing dan wel green marketing?

Hoewel uit deze vragen wellicht impliciet lijkt te volgen dat ik niet veel verwacht van de uitwerking van een purpose, is de conclusie van deze bijdrage juist dat ik voorstander ben van een expliciete benoeming van de purpose van de (vennootschap en de met haar verbonden) onderneming, waar bestuur en aandeelhouders in hun besluitvorming rekening mee te houden hebben.

Ik zet Timmermans stelling beknopt uiteen en plaats daar enkele kanttekeningen bij. In paragraaf 2 wordt de herkomst van het begrip purpose en het nut daarvan volgens Timmerman samengevat. In paragraaf 3 wordt het begrip purpose en de ratio van het vaststellen ervan nader besproken. Paragraaf 4 werpt enkele vragen op met betrekking tot de stakebolders in relatie tot purpose en de vennootschap (en de daarmee verbonden onderneming). Paragraaf 5 ziet op de verhouding tussen de purpose en het mission statement. Paragraaf 6 gaat in op purpose als greenwashing. In paragraaf 7 worden enkele afsluitende opmerkingen gemaakt.

\section{De oorsprong van de idee van purpose bij}

\section{besluitvorming: het vizier op langetermijnbelangen} Voor een verklaring van het begrip purpose neemt Timmerman de lezer mee naar de oorsprong van zijn gedachten over

5 Zie Timmerman 2021, p. 42-43. Zie voorts C.H.A. van Oostrum, Sustainability through transparency and definitions: A few thoughts on Regulation (EU) 2019/2088 and Regulation (EU) 2020/852, European Company Law (18) 2021, afl. 1, p. 15-21. 


\section{Maandblad}

Ondernemingsrecht

purpose. Hiervoor put hij inspiratie uit het managementdenken:

'In het management-denken zijn begrippen bedacht die in het vennootschapsrecht zijn opgenomen. Een voorbeeld hiervan is het oude, in de jaren twintig van de vorige eeuw ontwikkelde idee dat een onderneming een begroting voor het volgende boekjaar dient op te maken. (...) Een ander managementidee dat een plek in het vennootschapsrecht heeft gekregen, houdt in dat een onderneming een strategie dient op te stellen.'

De opname van het begrip 'strategie' in het vennootschapsrecht heeft tot gevolg dat 'ons vennootschapsrecht goed op de feitelijke gang van zaken in ondernemingen inspeelt en de toekomstgerichtheid van ondernemingen stimuleert', aldus Timmerman. Het vennootschapsrecht dient in zijn visie 'realitätsnah te zijn en toekomstgerichtheid te bevorderen'. Die toekomstgerichtheid zou worden versterkt door de formulering van een purpose. Aldus kijkt de ondernemingsleiding in zijn woorden 'nog juist iets verder in de toekomst en iets breder dan in een begroting of een strategie'. ${ }^{7}$ Het bestuur kan op die wijze leiding geven aan de onderneming met een specifieke purpose in gedachten en zo bijdragen aan de oplossing van maatschappelijke problemen als klimaatverandering en sociale ongelijkheid.

\section{Wat is purpose en welk probleem wordt ermee geadresseerd?}

Het formuleren van een purpose-verklaring heeft volgens Timmerman dus meerwaarde. Maar wat purpose precies behelst, is niet eenvoudig concreet te maken. Timmerman schrijft:

'In een purpose-verklaring wordt vastgelegd welk doel de vennootschap en de met haar verbonden onderneming in de samenleving nastreven en welke waarden en beginselen daarbij leidend zijn.'s

Hij citeert Edmans om aan te geven wat in een purpose-verklaring opgenomen kan worden: 'Why an enterprise exists, who it wants to serve, its reason for being and the role it plays in the world." Aldus zou de toekomstgerichtheid van de vennootschap en de met haar verbonden onderneming worden versterkt.

De contouren van het begrip purpose worden mijns inziens duidelijker als we het begrip afzetten tegen begrippen als strategie, doelomschrijving en mission statement. Timmerman noemt het begrip strategie expliciet, de doelomschrijving ter-

\footnotetext{
6 Timmerman 2021, p. 44

7 Timmerman 2021, p. 44

8 Timmerman 2021, p. 41-47.

9 Timmerman 2021, p. 44, onder verwijzing naar A. Edmans, Grow the pie, how great companies deliver both profit and purpose, Cambridge: Cambridge University Press 2020.
}

loops en laat het mission statement onvermeld. De eerste twee komen in deze paragraaf aan bod, het mission statement krijgt in paragraaf 5 nader de aandacht.

Timmerman gaat nader in op het begrip strategie en de verhouding tussen strategie en purpose. Het begrip strategie en het concept purpose zijn volgens hem nauw aan elkaar verwant. Beide zien op het langetermijndenken van de onderneming. Timmerman spreekt uitdrukkelijk over een purpose van de onderneming en niet van een purpose voor de vennootschap. ${ }^{10}$ Dit is niet zonder reden. Hij gebruikt het begrip strategie niet alleen om te illustreren dat bepaalde concepten uit het managementdenken voet aan de grond hebben gekregen in het vennootschapsrecht, hij gebruikt het ook om te beargumenteren dat de vaststelling van de purpose aan het bestuur voorbehouden zou moeten zijn. Timmerman acht het beheer over de purpose beter in handen van het bestuur dan van de aandeelhouders(vergadering). Ik kom hier later op terug.

Strategie is volgens Timmerman eigenlijk de uitwerking van de purpose voor een beperkt aantal jaren. Volgens Timmerman ligt het daarom in de rede om een purpose vast te laten stellen door het bestuur; het bestuur is immers ook belast met het formuleren van een strategie. ${ }^{11}$ En dit is de crux van de idee purpose die Timmerman propageert. Het bestuur zou bij het geven van leiding aan de onderneming ook de leiding moeten hebben bij het vaststellen van een purpose, en de purpose moet aldus buiten het bevoegdheidsbereik van de aandeelhoudersvergadering worden gehouden. ${ }^{12}$ Hetgeen via de statutaire doelstelling tot het terrein van de bevoegdheid van de aandeelhouders zou worden gerekend, wordt aldus aan de bestuursbevoegdheid toegevoegd.

Het behandelen van purpose en doelomschrijving als eenheden waartussen geen overlap bestaat, is niet per se een vanzelfsprekendheid. De invulling van een statutaire doelstelling van een vennootschap kan mijns inziens immers sterke overeenkomsten met die van een purpose bevatten. Ook de statutaire omschrijving van het doel kan een maatschappelijk doel, maatschappelijke waarden en beginselen noemen. Deze is bovendien naar buiten toe kenbaar door de opname in het handelsregister. Het huidige recht laat de mogelijkheid toe om in de doelomschrijving gewicht toe te kennen aan maatschappelijke belangen zoals de bijdrage aan de oplossing van bijvoorbeeld klimaatverandering. Toch makt Timmerman onderscheid tussen de purpose en de doelomschrijving. Hij lijkt met het begrip purpose een meer naar buiten toe, op de samenleving gerichte bestaansgrond te bedoelen:

'Purpose richt het vizier van ondernemingen en vennootschappen op de samenleving. In zo'n purpose-verklaring kan een onderneming bij voorbeeld aanduiden wat zij aan

10 Timmerman 2021, p. 42 en 45

11 Timmerman 2021, p. 45.

12 Timmerman 2021, p. 46 


\section{Maandblad}

Ondernemingsrecht

de oplossing van de hierboven genoemde maatschappelijke problemen wil bijdragen. ${ }^{.13}$

Het richten van de aandacht op de samenleving is niet onwelkom, gezien de door velen geuite kritiek 'dat ondernemingen door een overmatige oriëntatie op eigen financieel succes en daarmee gepaard gaande waardecreatie voor aandeelhouders onthecht zijn geraakt van de samenleving'. ${ }^{14}$

Timmerman behandelt in zijn bijdrage de doelomschrijving en de verhouding tot de purpose niet expliciet. Uit zijn stuk wordt wel het volgende duidelijk. Hoewel Timmerman voor grotere vennootschappen de opname van een verplichting tot het vaststellen van een purpose in Boek 2 BW voorstaat, is hij geen voorstander van de opname van een purpose zelf in de statuten. Het opnemen van de purpose in de statutaire doelomschrijving zou het dynamische karakter, dat essentieel is voor de purpose, aantasten. ${ }^{15}$

Critici zouden kunnen zeggen dat het plaatsen van de purpose buiten het bereik van de aandeelhoudersvergadering de vennootschappelijke verhoudingen zoals wettelijk geregeld verandert, en dat dat onwenselijk is. Het aanpassen van de wettelijke verhoudingen zou niet zonder meer moeten kunnen zonder daarvoor ook een basis in de wet te hebben. Het voorstel van Timmerman om de purpose buiten de doelomschrijving te houden, maar een verplichting tot het vaststellen van een purpose in het BW op te nemen, neemt deze kritiek de wind uit de zeilen. Wel wordt nog steeds een belangrijke bevoegdheid bij de aandeelhouders weggenomen.

Wanneer een purpose niet in de statuten wordt opgenomen, zou - voor zover de invulling van een specifieke purpose anders is dan die van het statutaire doel van de desbetreffende vennootschap - deze buiten de reikwijdte van artikel 2:7 BW, de doeloverschrijding, vallen. In het geval dat de noodzaak wordt gevoeld voor het vaststellen van een purpose, zou ik vanwege het belang dat aan die purpose wordt toegekend, meer voelen voor de opname van de purpose in de doelomschrijving.

Winter e.a. formuleren purpose als volgt:

'Goed geformuleerde basisbeginselen kunnen behulpzaam zijn bij het bepalen van de strategie gericht op dat uiteindelijke doel in de samenleving en kunnen bijdragen aan de intrinsieke motivatie van de betrokkenen binnen de onderneming (...) en zo het succes van de onderneming bevorderen. ${ }^{16}$

De vraag is dan wel wat bepaalt of een onderneming succesvol is. Is het succes van de onderneming bijvoorbeeld te meten aan de hand van de (eventueel als dividend uit te keren) winst, zoals dit het uitgangspunt lijkt te zijn in het shareholdersmodel? Of wordt het begrip winst breder getrokken, en moet worden gekeken naar de voordelen voor de samenleving als geheel? Volgens Timmerman kan namelijk een spanningsveld tussen winst en purpose ontstaan:

'Purpose en winst [in enge zin; JN] kunnen met elkaar op gespannen voet staan. Het geven van uitvoering aan een purpose kan de winst drukken. ${ }^{17}$

Het is daarom volgens hem belangrijk 'een goede, bij de betrokken onderneming passende mix van winst en purpose te vinden waarbij het oog gehouden dient te worden op lange termijn waardecreatie'.

Het antwoord op de vraag hoe deze mix gevonden moet worden, is volgens mij dan afhankelijk van een afweging van alle bij de onderneming betrokken belangen, passend bij het uitgangspunt van het belangenpluralisme in het vennootschapsrecht. Een terechte kanttekening bij de idee van het belangenpluralisme is volgens Timmerman dat dit een 'noodzakelijke, maar een niet zonder meer voldoende voorwaarde [is] om het klimaatbelang of andere specifieke belangen van zwaar gewicht in ondernemingen recht te doen'. ${ }^{18}$ Timmerman bekritiseert aldus de vrijblijvendheid van het belangenpluralisme en wellicht ligt hier ten dele de weerzin om de purpose in de doelomschrijving op te nemen en de behartiging daarvan over te laten als deelbelang in het vennootschappelijk belang. Het is mijns inziens echter de vraag of de formulering van een purpose het gesignaleerde probleem van vrijblijvendheid ondervangt. Bij het invullen en nader bepalen van beleid aan de hand van beginselen die in een purpose zijn vastgelegd, zullen toch ook een afweging van verschillende belangen van stakeholders en de prioritering van doelen van de vennootschap plaats moeten vinden. Purpose biedt ruimte aan een denken dat zich breder uitstrekt dan winst in enge zin alleen, maar geeft evenals het belangenpluralisme geen uitsluitende richting. Wel kan mijns inziens het accent binnen de belangenafweging door de invoering van een purpose verschuiven.

\section{Van shareholder primacy via purpose primacy naar people primacy}

De invoering van purpose heeft een bepaald 'doel'. Timmerman verwijst naar ideeën van Henderson:

'Zij wil een menselijker kapitalisme bereiken door ondernemingen ertoe te brengen om een purpose (een raison d'être of bestaansgrond) te formuleren en hieraan uitvoering te geven.'

13 Timmerman 2021, p. 44

14 Winter e.a. 2020, p. 474

15 Timmerman 2021, p. 44-45.

16 Zie Winter e.a. 2020, p. 473.

17 Timmerman 2021, p. 44

18 Timmerman 2021, p. 43. 


\section{Maandblad}

Ondernemingsrecht

Henderson bepleit aldus 'een zachtmoediger vorm van kapitalisme'. ${ }^{19}$

Timmerman put daarnaast inspiratie uit het werk van Mayer om te verduidelijken hoe purpose als richtlijn voor bijvoorbeeld de aandeelhouders kan werken. Voor de bewerkstelliging van het effectief zijn van purpose is het volgens Mayer noodzakelijk de rechten van bepaalde aandeelhouders te beknotten. Hiermee wordt het primaat aan purpose gegeven (purpose primacy). ${ }^{20}$ Ryan Burg is kritisch over de volgens hem op punten radicale ideeën van Mayer: 'The defense of an unequal distribution of shareholder power exemplifies this radicalism. ${ }^{21}$ Voorbeelden van structuren die Mayer voorstelt en die door Burg als radicaal worden gezien, zijn onder andere de familievennootschap, dual class shares, 'boards that appoint trustees to protect a firm's mission' en werknemers die als pensioenvoorziening aandelen krijgen. ${ }^{22}$

Burg gaat overigens wel voor een deel in de gedachte van Mayer mee dat betrokken aandeelhouders kunnen bijdragen aan een dialoog tussen aandeelhouders en bestuur:

'Mayer may be justified in preferring the close social relations of embedded ownership structures to the status quo standard of anonymous shareholding. Individual investors' subtle moral priorities are often drowned out by institutional intermediation. (...) blockholders are demonstrably more capable of sustaining a dialogue with management and governing for the long term. ${ }^{23}$

'Nevertheless', zo vervolgt Burg: 'agency and democratic theorists have reason to question Mayer's defense of unequal voting rights. ${ }^{24}$

Ook het Nederlandse recht gaat in beginsel uit van gelijke rechten voor aandeelhouders en daarbij dat de wens van de (gekwalificeerde) meerderheid leidend is. Voor de op grond van artikel 2:66/177 BW in de statuten opgenomen doelstelling van de NV respectievelijk de BV geldt dat deze steeds is te wijzigen. Wanneer men wil bewerkstelligen dat de wijziging van de statuten in beginsel onmogelijk moet zijn vanuit de wens om bepaalde maatschappelijke belangen daarin een permanente plaats te geven, is dit eigenlijk alleen te bereiken door steeds een meerderheid van de stemrechten in de aandeelhoudersvergadering te verzekeren. De vastlegging van de bescherming van publieke belangen in de doelstelling van overheids-

19 Timmerman 2021, p. 44, onder verwijzing naar R. Henderson, Reimagining capitalism. How business can save the world, Londen: Penguin Books 2020.

20 Zie C. Mayer, Prosperity. Better business makes the greater good, Oxford: Oxford University Press 2018.

21 R. Burg, Book reviews: Prosperity. Better business makes the greater good, by Colin Mayer, Business Ethics Quarterly (29) 2019, afl. 4, p. 546

22 Burg 2019, p. 546

23 Burg 2019, p. 546.

24 Burg 2019, p. 546 ondernemingen kent een soortgelijke problematiek. ${ }^{25}$ In zoverre valt het een en ander te zeggen ten voordele van de ideeën van Mayer ter bevordering van meer maatschappelijk georiënteerde vennootschappen.

Mayer meent dat met de formulering van een purpose ook het primaat bij de purpose komt te liggen. Hij noemt dit purpose primacy. ${ }^{26}$ In hoeverre purpose en purpose primacy een toegevoegde waarde ten opzichte van het in Nederland geaccepteerde stakeholdermodel hebben, is niet geheel duidelijk omdat de purpose in het algemeen niet als enige en uitsluitende doelstelling zal fungeren. Ook Burg signaleert dit aspect in de ideeën van Mayer:

'Mayer seems unaware of the stakeholder fairness arguments that run in the same direction, and focuses instead on a practical claim that purpose primacy is better able to establish and maintain trust so that corporations can sustain commitments. ${ }^{27}$

Een kanttekening bij de wenselijkheid van het vaststellen van purpose is de vraag of in Nederland - waar traditioneel gezien de belangen van stakeholders in de besluitvorming al zwaar wegen, met als voorlopige apotheose de uitspraak van 26 mei 2020 (Milieudefensie/Shell) ${ }^{28}$ - de positie van de aandeelhouder ten opzichte van het bestuur niet te ver wordt uitgehold.

\section{Oude wijn in nieuwe zakken? De verhouding tussen purpose en het mission statement}

Op punten bekruipt me bij de discussie over purpose een déjà-vugevoel. Zo is het bij veel ondernemingen geformuleerde mission statement mijns inziens sterk te vergelijken met de door Timmerman beschreven purpose. $\mathrm{Al}$ in de jaren zeventig van de vorige eeuw werd het begrip mission statement gebruikt bij Amerikaanse ondernemingen. Drucker stelde reeds:

'Defining the purpose and mission of the business is difficult, painful, and risky. But it alone enables a business to set objectives, to develop strategies, to concentrate its resources and to go to work. ${ }^{29}$

Een volledig en helder mission statement vormt de basis voor de acties van de onderneming. Andere doelen en corporate strategies kunnen alleen worden geformuleerd zodra de 'main reason for being' is beschreven. ${ }^{30}$

25 Zie J. Nijland, De overheidsonderneming, Deventer: Kluwer 2013. Hier moet overigens ook aandacht worden gegeven aan de begrenzingen die volgen uit de vrijverkeerregels.

26 Zie Mayer 2018

27 Zie Mayer 2018

28 Zie Rb. Den Haag 26 mei 2021, ECLI:NL:RBDHA:2021:5337.

29 P.F. Drucker, Management: Tasks, responsibilities, practices, New York: Harper \& Row 1974, p. 94.

30 P. Atrill, M. Omran \& J. Pointon, Company mission statements and financial performance, Corporate Ownership and Control (2) 2005, afl. 3, p. 28-35. 


\section{Maandblad}

Ondernemingsrecht

De ideeën omtrent purpose zijn zichtbaar in en vergelijkbaar met elementen uit deze omschrijving van mission statements. Beide hebben zeker een toegevoegde waarde. Het belang van een mission statement vis-à-vis de doelstellingen van de vennootschap kan worden beschreven als:

'[A] business [is] not being defined by its name, statutes or articles of incorporation, but by the business mission. Only a clear definition of the mission and purpose of the organisation makes possible clear and realistic business objectives. ${ }^{31}$

De invoering van een purpose kan een toegevoegde waarde hebben boven op of anders dan een mission statement. Een mission statement ziet wellicht eerder op het hoofddoel van de onderneming en is als zodanig intern gericht op het handelen van de onderneming, terwijl de purpose gericht is op het handelen van de onderneming voor anderen dan de onderneming an sich. Voor het duidelijk toevoegen van waarde moet de purpose in die zin - anders dan het mission statement - zich richten op de bevordering van maatschappelijke dan wel publieke belangen.

Overigens is interessant te zien dat mission statements meer kunnen zijn dan alleen het 'window dressen' van het doel van de onderneming als dividendgenerator voor de aandeelhouders. Er is weinig empirisch onderzoek naar mission statements, maar interessant is bijvoorbeeld het onderzoek van Hirota. Hij legde ruim negenhonderd mission statements van Japanse beursgenoteerde bedrijven aan de hand van bepaalde steekwoorden naast elkaar om te bezien in hoeverre deze bedrijven beter presteren dan andere. Hij concludeert dat een sterk mission statement de doelgerichtheid verbetert:

'[A] strong mission statement reinforces coordinative, goal-oriented, and motivational functions through a set of stable shared operational outcomes like technical innovation and product quality.' ${ }^{32}$

Mijns inziens is doelgerichtheid vormend voor een individu en zijn handelen. Dit geldt evenzo voor ondernemingen.

Mijns inziens geldt wat gezegd wordt over het mission statement ook ten aanzien van purpose. Een helder geformuleerde purpose kan bevorderen dat het bestuur het vizier naar buiten richt en op de dienstbaarheid van de vennootschap om bij te dragen aan het oplossen van bepaalde maatschappelijke problemen. Het lijkt mij daarbij in tegenstelling tot Timmerman nuttig de purpose in de statuten vast te leggen. Zonder de purpose vast te leggen in de statuten, maar deze alleen jaarlijks terug te laten komen als bestuursbesluit, is het mijns inziens las-

31 A. Campbell \& K. Tawadey, Mission and business philosophy, Oxford: Butterworth-Heinemann2016, p. 288.

32 S. Hirota, P. Hong, K. Kubo, H. Miyajima \& Y.W. Park, Corporate mission, corporate policies and business outcomes: Evidence from Japan, Management Decision (48) 2010, afl. 7, p. 1134-1147. tig in te zien hoe purpose meer dan alleen een richtsnoer voor het bestuur van de vennootschap zou kunnen zijn. De impact van purpose zou mijns inziens worden vergroot door deze in de statuten vast te leggen.

Purpose kan de verhoudingen tussen organen beïnvloeden. Timmerman stelt dat

'de aandeelhoudersvergadering in haar besluiten niet in strijd met het door het bestuur vastgestelde purpose mag handelen. (...) De aandeelhoudersvergadering mag een bevoegd vastgestelde strategie en een bevoegd vastgestelde purpose niet negeren.'

Gevolg is volgens Timmerman dat het bestuur met succes vernietiging zou kunnen verzoeken 'wegens strijd met de redelijkheid en billijkheid van een besluit van de aandeelhoudersvergadering dat evident in strijd is met de purpose (art. 15 lid 1, sub b BW)'. Toch moet ook hij dit relativeren, want uiteindelijk heeft de aandeelhoudersvergadering natuurlijk wel de bevoegdheid het bestuur te ontslaan en nieuwe bestuurders te benoemen, of zoals Timmerman het formuleert:

'Wel is het in beginsel toegelaten dat de aandeelhoudersvergadering met behulp van haar vennootschappelijke bevoegdheden bestuurders ontslaat ingeval zij geen vertrouwen in het bestuur heeft, wanneer dit een purpose heeft vastgesteld dat bij de aandeelhouders op grote weerzin stuit (art. 2:132/242 BW). ${ }^{33}$

Deze constatering neemt niet weg dat de rol van de principaal verandert. Interessant punt bij het invoeren van een purpose voor de onderneming is namelijk dat deze vanuit de principal agent theory bezien weerslag kan hebben op de status van organen. Met de invoering van een purpose kan worden afgevraagd of het bestuur niet alleen agent is voor de aandeelhouder, maar ook voor de maatschappij als geheel. Zie de door Timmerman gesignaleerde Europese en ook Nederlandse tendensen.

Dat Timmerman voor het geven van inhoud aan purpose sterk op de lijn van het belangenpluralisme leunt, blijkt uit zijn idee om bij een grotere vennootschap naast de aandeelhoudersvergadering en de raad van commissarissen ook een raad van maatschappelijke vertegenwoordigers in te stellen 'waarmee regelmatig overleg plaatsvindt over de vraag of de purpose nog adequaat is en of in voldoende mate binnen de betrokken onderneming uitvoering aan de purpose wordt gegeven' ${ }^{34} \mathrm{Het}$ overleg zou bijdragen aan het dynamische karakter van de purpose. Het bepalen van de samenstelling van een dergelijke raad

33 En ook die mogelijkheid kan op haar beurt weer worden gerelativeerd: 'In een dergelijk geval zou het bestuur van een Nederlandse beursvennootschap ter bescherming van zijn positie nog wel de responstijd van maximaal 180 dagen kunnen inroepen (zie gedragsregel 4.1 .6 en 4.1 .7 van de Corporate Governance Code). Hierdoor kan besluitvorming over ontslag worden uitgesteld of op de lange baan geschoven worden.'

34 Timmerman 2021, p. 46. 


\section{Maandblad}

Ondernemingsrecht

is geen sinecure. Met de purpose en het belang daarvan voor de maatschappij in gedachten zou deze raad bijvoorbeeld een representatieve afspiegeling moeten zijn van de bevolking en derhalve van de vertegenwoordigers in de Tweede Kamer. Volgens mij stelt Timmerman een niet door de overheid samengestelde raad voor. Wellicht is dat nog niet representatief genoeg. Moeten alle landen waarin de vennootschap actief is, worden vertegenwoordigd? Hoe zit het met brievenbusfirma's? Ook is de vraag: hoe om te gaan met toekomstige generaties? Moeten die ook worden vertegenwoordigd? Door wie? En wat te denken van dieren? Geloofsgemeenschappen?

\section{Greenwashing en verantwoording}

De vaststelling van purpose alleen is niet genoeg. Alleen bij ondernemingen waar Environmental Social Governance (ESG) al op orde is, zal een nadere invulling via de purpose 'realitätsnah' zijn. In de andere gevallen zal het vastleggen van een purpose niet bijdragen aan een wezenlijke verandering van ondernemingen en hun bestaansredenen. Vergelijk in dit kader de opmerkingen die zijn gemaakt over de verklaring van de Business Roundtable: niet alleen zijn de meeste van de ondernemingen op de lijst onder deze verklaring gevestigd in Delaware (met een sterk op de aandeelhouders gefocust karakter), maar ook blijkt dat de verklaring niet door het volledige bestuur is ondersteund, maar dat slechts de CEO deze heeft getekend.

Of een verantwoordingsplicht over de wijze waarop uitvoering is gegeven aan de bestaansgrond afdoende is om 'purpose washing' te voorkomen, zoals Winter betoogt, ${ }^{35}$ vraag ik mij af. Uiteindelijk wordt deze verantwoording door het bestuur onder het huidige wettelijke systeem aan de aandeelhouders afgelegd. ${ }^{36}$ Wordt aldus niet te veel van vennootschappen en hun aandeelhouders verwacht? Er is wellicht eerder een rol weggelegd voor het bestuur. Deze gedachte lijkt de basis te vormen voor het voorstel om een zorgplicht voor het bestuur, dat onder toezicht staat van de raad van commissarissen, te introduceren. De purpose zou hierbij een belangrijke rol kunnen vervullen:

'De purpose dient dan als een concrete invulling van wat de zorgplicht in de context van de eigen vennootschap vraagt. Zij geeft richting aan besluitvorming en oriëntatie van de vennootschap en aan de invulling van open normen waaraan de rechter toetst in aansprakelijkheidsprocedures en het enquêterecht. Zij geven inhoud aan wat de redelijkheid en billijkheid van betrokkenen in de vennootschappelijke verhoudingen verlangen (art. 2:8 BW). ${ }^{37}$

\section{Afsluitende opmerkingen}

Timmerman heeft met zijn bijdrage het debat over purpose verdiept en zet met de historische verbinding die hij legt tussen

35 Winter e.a. 2020.

36 De facto soms ook aan belangenorganisaties. De overheid stuurt hier soms ook op. Zie bijv. www.transparantiebenchmark.nl/over-dekristalprijs.

37 Winter e.a. 2020, p. 473 het managementdenken en de ontwikkeling van het ondernemingsrecht de toon voor toekomstige discussies over purpose. Waartoe is de vennootschap op aarde? Indien bijvoorbeeld de verduurzaming van de onderneming wordt beoogd, heeft het zin om richting te geven aan de onderneming door het vaststellen van haar purpose. Deze is, mits helder geformuleerd, aldus richtinggevend voor de betrokkenen bij de onderneming, meer specifiek de organen van de vennootschap waarin de onderneming wordt gedreven. Timmerman bepleit tegelijkertijd dat de verantwoordelijkheid voor het behartigen van maatschappelijke belangen niet bij de aandeelhouder moet worden gelegd, maar bij het bestuur. Timmerman lijkt niet onwelwillend te staan tegenover de dienstbaarheid van de vennootschap aan de onderneming. Doordat ondernemingsrechtelijke begrippen een rol gaan spelen in het vennootschapsrecht lijkt de focus van het vennootschapsrecht volgens Timmerman te verschuiven van de vennootschap als aandeelhoudersverband naar de onderneming. ${ }^{38}$ Voor het verband dat Timmerman legt tussen de strategie en de purpose, en de daaruit volgende conclusie dat de bevoegdheid hierover derhalve onder het bestuur moet vallen, valt wellicht wat te zeggen, maar deze stelling valt niet goed te rijmen met de wettelijke bevoegdheid van de aandeelhouders om de statutaire doelstelling vast te stellen. Wel meen ik met Timmerman dat purpose een dynamisch concept zou moeten zijn. Mijns inziens hoeft de opname in de statutaire doelomschrijving echter geen verstarring te betekenen. Het bestuur moet immers de strategie van de onderneming, die een uitwerking van de purpose is, steeds opnieuw heroverdenken. Indien purpose van wezenlijk belang wordt geacht, heeft een opname daarvan in de doelstelling mijns inziens, in tegenstelling tot Timmerman, echter wel de voorkeur.

Wat purpose precies is en hoe deze zich verhoudt tot andere begrippen zoals het mission statement kan nog verder worden uitgewerkt. Dit neemt niet weg dat een purpose, indien beoogd, het accent kan leggen op het daarin vervatte doel van de onderneming, zodat een 'zachtmoediger vorm van kapitalisme' kan worden bevorderd.

Ik ben derhalve niet zo kritisch over Timmerman als Burg over Mayer, wanneer hij stelt:

'Mayer's theory of corporate consciousness obscures more than it clarifies, particularly in light of his prediction that artificial intelligence will soon establish firms' purposes. A simpler path for purpose primacy is through a stakeholder model. It need only grant that purposes come from people and groups and also recognize that firms can be organized to serve different stakeholder communities. ${ }^{39}$

Het vaststellen van purpose verruimt ook mijns inziens de blik van de bestuurders en commissarissen van de vennootschap en

38 Timmerman 2021, p. 47

39 Burg 2019, p. 549. 


\section{Maandblad}

Ondernemingsrecht

kan zo bijdragen aan de positieve bijdrage van de onderneming aan bijvoorbeeld de verduurzaming van de wereld.

\section{Naschrift L. Timmerman}

Ik voel mij vereerd door en ben dankbaar voor de aandacht die J. Nijland aan mijn beschouwing over purpose heeft gewijd. Ik makk een korte opmerking over het punt dat ons verdeeld houdt (zonder - hoop ik - in herhaling te vervallen). Nijland verdedigt dat een door het bestuur uitgedachte purpose in het statutaire doel vastgelegd dient te worden. Ik zie dat anders. Het gevolg van het idee van Nijland is dat de aandeelhouders over de purpose het laatste woord hebben. Ik vind dat niet wenselijk. De beschouwing van Nijland bevat een mooi citaat:

'[A] business [is] not being defined by its name, statutes or articles of incorporation, but by the business mission. Only a clear definition of the mission and purpose of the organisation makes possible clear and realistic business objectives.'

Dit citaat refereert aan een ontwikkeling in het vennootschapsrecht die mij fascineert. Deze komt erop neer dat de vennootschap in verhouding tot de onderneming aan gewicht verliest. Vennootschapsrecht krijgt trekken van ondernemingsrecht. Ik wil die ontwikkeling versterken. Daarin past het niet dat de aandeelhoudersvergadering het laatste woord over de inhoud van de purpose heeft. Mijn bezwaar is dat de aandeelhoudersvergadering in de eerste plaats op de eigen financiële belangen is gericht. Dat mag, maar zo'n instantie is niet geschikt om een purpose vast te stellen die een veelheid van belangen en waarden dient te omvatten. Het bestuur van een vennootschap dient mijns inziens breed overleg over de inhoud van de purpose te voeren. Dat sluit overleg van het bestuur met de aandeelhouders over de purpose niet uit. Ik vind het een mooie ontwikkeling dat het bestuur van Shell zijn klimaatbeleid - dat is een onderdeel van de purpose - onlangs aan een adviserende stemming van de aandeelhoudersvergadering heeft onderworpen. Door die stemming vonden allerlei belangwekkende discussies plaats. Overigens ben ik niet van mening dat het bestuur van een onderneming agent van de maatschappij als geheel zou dienen te zijn, zoals Nijland opwerpt. Neen, primaire taak van het bestuur is om het bestendige succes van de door de vennootschap gedreven onderneming te bevorderen. Dat is de hoofdtaak van het bestuur, waarbij een goed uitgewerkte purpose, een strategie en begrotingen belangrijke hulpmiddelen zijn, zoals ik in mijn beschouwing heb uiteengezet. De onderneming in al haar dimensies staat bij mij centraal. 